\title{
Successful pregnancy after previous uterine rupture
}

\section{Shamrao Ramji Wakode, Varsha Narayana Bhat*}

Department of Obstetrics and Gynaecology, Dr S. C. GMC. Nanded, Maharashtra, India

Received: 14 November 2020

Accepted: 04 January 2021

\section{*Correspondence:}

Dr. Varsha Narayana Bhat,

E-mail: chvarshanbhat@gmail.com

Copyright: () the author(s), publisher and licensee Medip Academy. This is an open-access article distributed under the terms of the Creative Commons Attribution Non-Commercial License, which permits unrestricted non-commercial use, distribution, and reproduction in any medium, provided the original work is properly cited.

\section{ABSTRACT}

Uterine rupture is a rare and catastrophic event with high fetal and maternal morbidity rate. It is most commonly seen in scarred uterus. Here we present a case of 30 years old female, gravida 3 para 2 living 0 with previous spontaneous uterine rupture at 28-30 weeks with still birth 3 years ago. She underwent emergency laparotomy with repair. She conceived spontaneously, admitted at 20 weeks of gestational age and close antenatal surveillance was done throughout the pregnancy. Corticosteroids was administered. At 36 weeks elective caesarean was planned, delivering via breech presentation to a live male baby of $2.5 \mathrm{~kg}$, Apgar score of 8/10,9/10 at 1 and 5 minutes.

Keywords: Caesarean delivery, Uterine rupture, Pregnancy

\section{INTRODUCTION}

Uterine rupture is classified as complete when all layers of the uterine wall are separated and incomplete when muscle is separated but visceral peritoneum is intact which is referred as dehiscence. Morbidity and mortality are highest with complete rupture and it is considered as one of the serious obstetric emergencies.

The increase in the caesarean rates, use of prostaglandins, attempts at vaginal delivery in a scarred uterus have contributed to uterine rupture in recent years. ${ }^{1-3}$ The incidence of rupture in an unscarred uterus is being 1 in 8000 deliveries. $^{4}$ For a women with history of uterine rupture the recurrence risk of uterine rupture ranges in the literature from $4-33 \% .{ }^{4}$ In women undergoing trail of labor after caesarean section the risk of rupture is 0.2 $1 \% .^{5}$ Pregnancy after uterine rupture is not widely advised and patients had undergone hysterectomy or tubal ligation in the past but with the modern evolving practices, preservation of fertility can be considered in young patients with proper obstetric care and emphasis on time and mode of delivery.

\section{CASE REPORT}

A 30 years old female, para 2 living zero had visited OPD with previous reports- first emergency LSCS for term transverse lie turned out to be fresh still birth male child, secondly spontaneous uterine rupture at 28 -30 weeks of pregnancy for which she had undergone laparotomy and delivered a fresh still birth male baby with rupture at the lower uterine segment extending laterally up to fundus at right side was noted. Patient had consulted 2-3 times after laparotomy, pre-pregnancy counselling was done for 2-3 years. Couple were frustrated and had expressed their desire of having a new child by accepting all the consequences that can occur throughout her course of pregnancy. Patient had conceived spontaneously. She had her first antenatal visit at $10^{\text {th }}$ weeks of gestation where she had undergone thorough clinical examination with dating scan and other laboratory investigations. Anomaly scan was done at $18-20^{\text {th }}$ weeks of gestation and she was hospitalised after that and kept under observation in highrisk ANC ward. Scar assessment was done at 30 weeks of gestation and found to be $2.5 \mathrm{~mm}$. IM Dexamethasone $12 \mathrm{mg} 2$ doses 12 hours apart were administered for fetal lung maturity. Pregnancy was uneventful till 34-35 weeks except for the vague abdominal pain which was probably 
due to stretching of previous adhesions.

Patient was advised to pay attention to fetal movements, abdominal pain and uterine contractions.

At 36 weeks of gestation patient was posted for elective caesarean section and abdomen was opened by Pfannenstiel incision in layers, dense adhesions of anterior abdominal wall to posterior rectus sheath were noted. Rectus sheath was adherent along with omentum to previous uterine scar site. Right lateral pervious scar was intact and thick. Uterus was opened horizontally. A full-term male baby of $2.5 \mathrm{~kg}$ was delivered by breech with Apgar being 8/10 and $9 / 10$ at 1 and 5 minutes respectively. Uterus was not exteriorized due to dense bladder and omental adhesions and hence sutured in situ. Abdomen closed in layers. Post-operative period was uneventful. Patient was discharged from the ward on $10^{\text {th }}$ postoperative day. Upon follow up at 15 days both patient and baby were healthy.

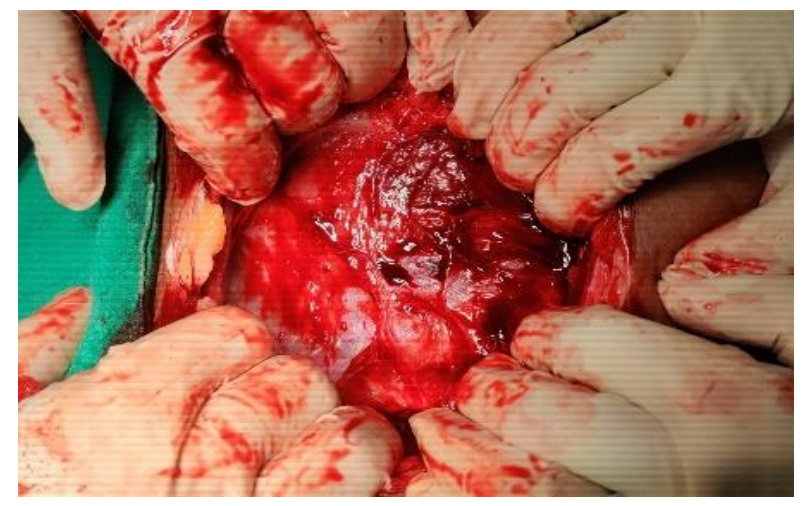

Figure 1: Posterior rectal adhesions to anterior wall of uterus.

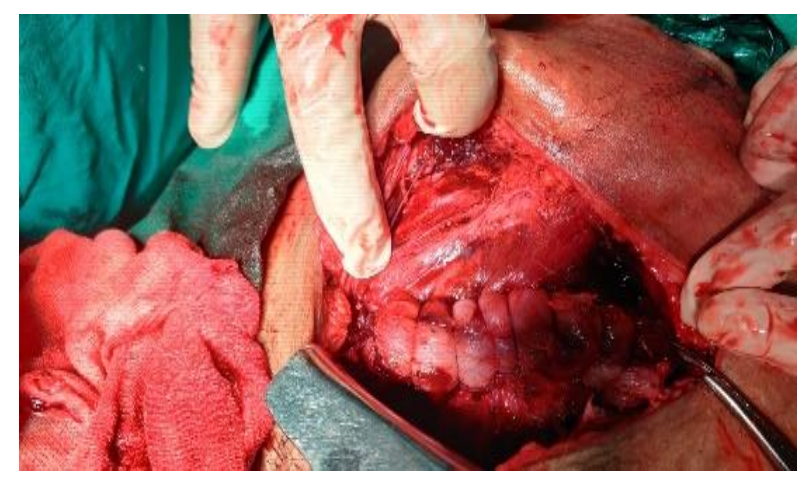

Figure 2: Uterine closure in previous ruptured uterus.

\section{DISCUSSION}

Pregnancy following the diagnosis of dehiscence or uterine rupture is a known risk factor for repeated rupture, which is associated with significant maternal and fetal morbidity and may end up in caesarean hysterectomy, hence advisable not to conceive again. In our case the women who had conceived after previous rupture belongs to an ignoramus population characterised by avoidance of contraception, high parity and discordance to termination of pregnancy. The recurrence rate of uterine rupture is reported to be $4.8-19 \%$ with highest risk of recurrence seen in women with history of ruptured upper uterine segment. ${ }^{7}$ The management of uterine rupture varies from conservative repair to hysterectomy depending on extent of rupture, location and associated morbid condition of the patient. Based on the different studies caesarean section must be planned between $36-38$ weeks of gestation., ${ }^{4,6-8,10}$ Those with ruptured lower uterine scar delivery at 37-38 weeks of gestation is recommended. For ruptured upper uterine scar delivery at 35 weeks of gestation or admission to hospital 1 week prior to the gestation age at which labor started in the previous pregnancy. Like in our case patient was admitted at 20 weeks of gestation onwards, corticosteroids were administered and wait and watch protocol was followed until 37 weeks as done by Fox et $\mathrm{al}^{4}$

The risk of recurrence was higher when the previous rupture was longitudinal and interval between subsequent pregnancy and rupture was shorter and also the gestational age at which ruptured had occurred. ${ }^{9}$ These factors should be kept in mind by the obstetrician and should utilize ancillary imaging to anticipate recurrence and also avoid unnecessary interventions that may lead to delivery of premature infants.

\section{CONCLUSION}

The incidence of uterus rupture is significantly higher in developing countries than developed ones due to poor antenatal and obstetric care, home deliveries, multiparity, prolonged labor etc. Medical induction or augmentation of labor can cause iatrogenic risk for rupture of the uterus. Because of the rare incidence and a specific presentation, rupture of the uterus may be difficult to detect. Pregnancy after uterine rupture can be successful if proper obstetric care is provided with focus on time and mode of delivery i.e., planned caesarean delivery before the onset of labor. If delivery is planned before 37 weeks of gestation, corticosteroid administration must be considered to reduce morbidity due to neonatal respiratory distress. Patients education about dehiscence or recurrence of uterine rupture and early seek of medical help can reduce the fetal and maternal morbidity.

\section{Funding: No funding sources \\ Conflict of interest: None declared \\ Ethical approval: Not required}

\section{REFERENCES}

1. Turner MJ. Uterine rupture. Best Pract Res Clin Obstet Gynaecol. 2002;16:6979.

2. Landon MB, Hauth JC, Leveno KJ, Spong CY, Leindecker S, Varner MW et al. Maternal and 
perinatal outcomes associated with a trial of labor after prior cesarean delivery. $\mathrm{N}$ Engl $\mathrm{J}$ Med. 2004;351:25819.

3. Khabbaz AY, Usta IM, El-Hajj MI, Abu-Musa A, Seoud M, Nassar AH. Rupture of an unscarred uterus with misoprostol induction: case report and review of the literature. J Matern Fetal Med. 2001;10:1415.

4. Fox NS, Gerber RS, Mourad M, Saltzman DH, Klauser CK, Gupta S et al. Pregnancy outcomes in patients with prior uterine rupture or dehiscence. Obset Gynecol. 2014;123(4):7859.

5. Motomura K, Ganchimeg T, Nagata C, Ota E, Vogel $\mathrm{JP}$, Betran AP et al. Incidence and outcomes of uterine rupture among women with prior caesarean section: WHO Multicountry Survey on Maternal and Newborn Health. Scientific reports. 2017;7:44093.

6. Larrea NA, Metz TD. Pregnancy After Uterine Rupture. Obstet Gynecol. 2018;131(1):135-7.

7. Chibber R, El-Saleh E, Fadhli RA, Jassar WA,
Harmi JA. Uterine rupture and subsequent pregnancy outcome-how safe is it? A 25-year study. J Matern Fetal Neonatal Med. 2010;23(5):421-4.

8. Usta IM, Hamdi MA, Musa AA, Nassar AH. Pregnancy outcome in patients with previous uterine rupture. Acta Obstet Gynecol Scand. 2007;86(2):172-6.

9. Shick S, Neiger R. Pregnancy outcome in women with history of uterine rupture or dehiscence. Obstet Gynecol cases Rev. 2015;2:5.

10. Delecour L, Rudigoz RC, Dubernard G, Huissoud C. Pregnancy and delivery after complete uterine rupture. J Gynecol Obstet Hum Reprod. 2018;47(1):23-8.

Cite this article as: Wakode SR, Bhat VN.

Successful pregnancy after previous uterine rupture.

Int J Reprod Contracept Obstet Gynecol 2021;10:784-6. 